\title{
How and When Factors of Agricultural Contribution Influence Urbanization: A Historical Analysis of Tibet
}

\author{
Song Liu $\left(\mathbb{D},{ }^{1}\right.$ Ming Li $\left(\mathbb{D},{ }^{2}\right.$ Ying Liu $\left(\mathbb{D},{ }^{1}\right.$ Fangzhou Ni ${ }^{(D)},{ }^{3}$ and Chunshan Zhou ${ }^{1}{ }^{1}$ \\ ${ }^{1}$ School of Geography and Planning, Sun Yat-sen University, No. 135, Xingang Xi Road, Guangzhou 510275, China \\ ${ }^{2}$ Land Consolidation and Rehabilitation Center of Ministry of Land and Resources, No. 37, Guanyingyuan West, \\ Xicheng District, Beijing 100035, China \\ ${ }^{3}$ School of Architecture, University of Southern California, 3551 Trousdale Pkwy, Los Angeles 90089, USA \\ Correspondence should be addressed to Chunshan Zhou; zhoucs@mail.sysu.edu.cn
}

Received 15 April 2021; Revised 7 November 2021; Accepted 26 November 2021; Published 21 December 2021

Academic Editor: Benjamin Miranda Tabak

Copyright (c) 2021 Song Liu et al. This is an open access article distributed under the Creative Commons Attribution License, which permits unrestricted use, distribution, and reproduction in any medium, provided the original work is properly cited.

Agriculture Powers Urbanization. How and when agriculture influences urbanization in underdeveloped regions remain poorly understood from an agricultural contribution perspective, specifically the food contribution (FDC), raw materials contribution (MLC), labor contribution (LRC), and market contribution (MTC). This study investigated this issue in the context of Tibet. A Granger causality test (GCT), the impulse response function (IRF), and variance decomposition (VD) were used. The GCT results demonstrated that agricultural contribution factors (ACFs), Granger-cause urbanization, and the IRF and VD results demonstrated that the influences of ACFs on urbanization were various and asynchronous. Both MTC and LRC quickly and positively respond to urbanization; however, LRC currently influences urbanization, whereas MTC influences urbanization currently and in the future. Both MLC and FDC negatively and slowly respond to urbanization; however, MLC currently influences urbanization, whereas FDC will influence urbanization in the future. This study's findings depict changing trajectories of the role of ACFs in urbanization, elucidating urban-rural transformation.

\section{Introduction}

Urbanization or rural-to-urban transition, an important issue in the urban-rural dual system, is a long-standing topic of research. Research on the mechanisms of urbanization has theoretically recognized the roles of agriculture [1]; vertical disintegration $[2,3]$; producer service expansion [4]; economic growth [5]; rural-to-urban migration in accordance with the Ranis-Fei model [6] and the push-pull hypothesis [7]; income expectations [8, 9]; capital accumulation [10]; spatial production [11]; and network society [12].

Theorists have recognized the outsized influence of agriculture in the initial stage of urbanization [13-15]; this influence is due to the large demand for agricultural surplus products, which is driven by the expansion of cities. Recent empirical studies have reported that changes in agricultural activity, particularly the expansion of soybean exports, have promoted urban growth in Brazil $[16,17]$ and have exerted both beneficial and harmful effects on urbanization in India
[18]. Thus, according to theoretical and empirical evidence, agricultural development promotes urbanization. However, when and how agriculture influences urbanization have yet to be analyzed with reference to the aforementioned theories.

The Tibet Autonomous Region has experienced noticeable agricultural modernization and urban development. In 2019, 68 laborers produced 10,000 RMB in agricultural output value, which was only one-seventh of the 466 laborers in the corresponding 1990 figure. Furthermore, in 2019, Tibet's agricultural gross output value reached 21.3 billion RMB ( 2 billion RMB in 1990), and the region's grain yield reached 1.05 million $t(0.61$ million $t$ in 1990). Together with such growth in agricultural production, Tibet's total population has also grown from 2.18 million people in 1990 to 3.51 million people in 2019, and the urbanization rate in Tibet, which reached $31.54 \%$ in 2019 , is continually increasing. Agricultural modernization makes agriculture less labor intensive, which in turn frees up people who would otherwise work in agriculture to work in the city, thus 
increasing the urbanization rate. However, according to Chen et al. [19], if agricultural modernization lags behind the pace of urbanization, it hinders urbanization, but if it develops ahead of the pace of urbanization, it puts pressure on urbanization because of the corresponding shortage of food and the corresponding glut of laborers in the urban labor market. For example, in 2019, 494,000 workers in rural Tibet worked in nonagricultural industries; this figure is much higher than the corresponding figure of 50,000 in 1990. The migration of rural workers to cities also puts pressure on city infrastructure.

Therefore, agriculture does not straightforwardly promote urbanization under all circumstances. Correspondingly, the contexts under which agriculture promotes or hinders the urbanization process have constituted a key topic of research in agriculture's relationship with urbanization. In particular, Chang [1] and Johnston and Meller [20] have theoretically recognized that agriculture benefits cities by providing food contribution (FDC), raw materials contribution (MLC), labor contribution (LRC), and market contribution(MTC).

In this present era of postindustrialization and global urbanization, studies have focused on developed regions when theorizing the roles of industrialization and financialization in urbanization [21-23], neglecting agriculture's role in the urbanization process in underdeveloped regions, especially from the perspective of agriculture's contribution to urbanization. This gap in the literature must be filled not only because agriculture provides goods that are necessary to urbanization, but also because agriculture aids poverty reduction and economic growth [24].

With consideration of advances in urbanization, this study investigated the roles played by agricultural contribution factors (ACFs; i.e., FDC, MLC, LRC, and MTC) in the urbanization process in Tibet, an underdeveloped region of China. ACFs are also of particular importance for other underdeveloped regions, where urbanization is theoretically characterized as slowly increasing [25] and being powered by industrialization [26]. This study answered the following questions: What was the role of ACFs in urbanization? How and to what extent have the ACFs affected urbanization, especially in the short and long term?

\section{Literature Review}

In recent decades, theoretical inquiry into the relationship between agriculture and urbanization has changed much in terms of its fundamental approach. Early research had emphasized agriculture's relationship with economic growth, whereas newer research has emphasized agriculture's role in stimulating urban development $[18,24]$.

Traditionally, economic growth was considered to create job opportunities in the city, widen the urban-rural income gap, attract migrants, and promote industrial concentration $[7,27]$. This traditional conception, however, has been contested. Studies have demonstrated that although agriculture drives economic growth in developing countries $[28,29]$ by supporting secondary- and tertiary-sector growth through demand and production linkages [30], the effects of these linkages on economic growth are negligible in developed countries [31].

The increase in agricultural productivity is an important stimulus through which labor streams to the manufacturing sector, which in turn accelerates urban development [32]. In India, Africa, and Brazil, the green revolution, which was aimed at increasing agriculture productivity, promoted the development of agricultural activity. India has witnessed rapid urbanization [33, 34]. Tripathi and Rani [18] found that, with respect to agricultural growth, the male workforce in the rural agriculture sector slowed the pace of urbanization and increased expenditure on agriculture and fertilizer increased the pace of urbanization. In African countries, strong linkages were found between agriculture and urbanization; specifically, the urbanization rate increased by approximately 0.5 standard deviations with a one-standard-deviation decrease in the agricultural value produced yearly [35]. Furthermore, because African countries cannot bypass a broad-based agricultural revolution to successfully launch their economic transformations [36], such countries have leveraged the stronger links between agriculture and small towns to transition into inclusive development, specifically in economic growth and poverty reduction [24]. In Brazil, soybean agriculture has also led to socioeconomic changes in cities [16]. The expansion of export-driven soybean agriculture promotes urban development by increasing the demand for services, housing, and goods to nonagricultural sectors, providing these sectors with workers and capital [17].

Chinese researchers have acknowledged that agricultural modernization, industrialization, and urbanization constitute a complete system, in which agricultural modernization supports industrialization [19]. Empirical studies have found that agricultural modernization is a Granger cause of urbanization in Xinjiang and Jilin provinces; however, the effects vary in the long and short term $[37,38]$.

The forces driving Tibetan urbanization have also been discussed. Before China's 1979 opening-up reforms, the executive branch of government was the main force promoting Tibet's urban development [39, 40]. However, after 1979 , economic forces (such as tourism) were more influential in promoting Tibet's urban development [41]. The role of agriculture in this development, however, has been neglected in the literature.

The literature has elucidated agriculture's contribution to urbanization, but some shortcomings remain. First, the effects of agricultural factors on urbanization in underdeveloped regions have not been investigated, especially in Tibet; more attention has been paid to the nonagricultural factors affecting urbanization dynamics in developed regions. Second, empirical studies on the relationship between agriculture and urbanization have rarely focused on agricultural contributions; these studies have instead focused on agricultural activities. Third, the mechanisms through which agricultural activities influence urbanization in Tibet remain unidentified.

The literature has elucidated the interrelationships between agriculture and urbanization, but it has not elucidated how agriculture influences urbanization processes in underdeveloped regions from the perspective of agricultural contribution. The theory of agricultural contributions 
introduced by Chang [1] (pp. 187-194) helps fill this gap in the literature.

To bridge these gaps in knowledge, the researchers of this study considered the role of agricultural contributions in the causal links between agriculture and urbanization. By doing so, this study made two main contributions to the literature. First, the causal links between agriculture and urbanization were investigated. Second, agriculture's role in urbanization was further elucidated from the perspective of agricultural contributions. In general, this study's findings contribute to the body of scientific knowledge on the dynamics of agriculture-driven urbanization.

\section{Materials and Methods}

3.1. Study Area Description. Tibet Autonomous Region, located at an average altitude greater than 4000 meters, has shaped aid-oriented development model through national level development policies [42].

Since the reform and opening up, CPC Central Committee held seven "Work Forum on Tibet" (WFT) and put forward phased tasks of agriculture and urban development projects in Tibet. The third WFT (In 1994) focused on the construction of agriculture, basic industries, and infrastructures. In 2010, the fifth WFT put forward projects on the development of economic and people's livelihood. In 2020, in the new WFT, China government proposed blueprints to build a new socialist modern Tibet with unity, prosperity, civilization, harmony, and beauty [43].

The aid-oriented urbanization model, which is quite different from the industrialized-and financialized-oriented urbanization model in most of developed coastal China [44-46], has transformed Tibet into an atypical dual economic structure. In the atypical dual economic structure, agricultural and nonagricultural sectors are separated and show low correlations with each other [47]. However, the agricultural modernization witnessed positive effects on urbanization by providing necessary agro-products to the cities as well [48]. Under such circumstances, the role of agricultural contributions in urbanization may differ from the theory. Thus, Tibet Autonomous Region was selected for study.

3.2. Research Hypotheses. As the source of industrialization, agriculture contributes to urbanization through FDC, MLC, LRC, and MTC $[1,20]$. The mechanisms that link ACFs to urbanization are illustrated in Figure 1. The mechanisms are threefold.

First, food supply is either a promoter or constrainer of urbanization. Food is a product supplied by farms and is consumed by those working in industry [1]. The increase in population and national income from urbanization places stress the food supply; if such stresses are alleviated by improving farming productivity through industrialization [1] or by importing food, developed industries compete with the agricultural sector for resources because of a higher marginal output in urban regions compared with rural regions [49]. Therefore, an abundant food supply promotes

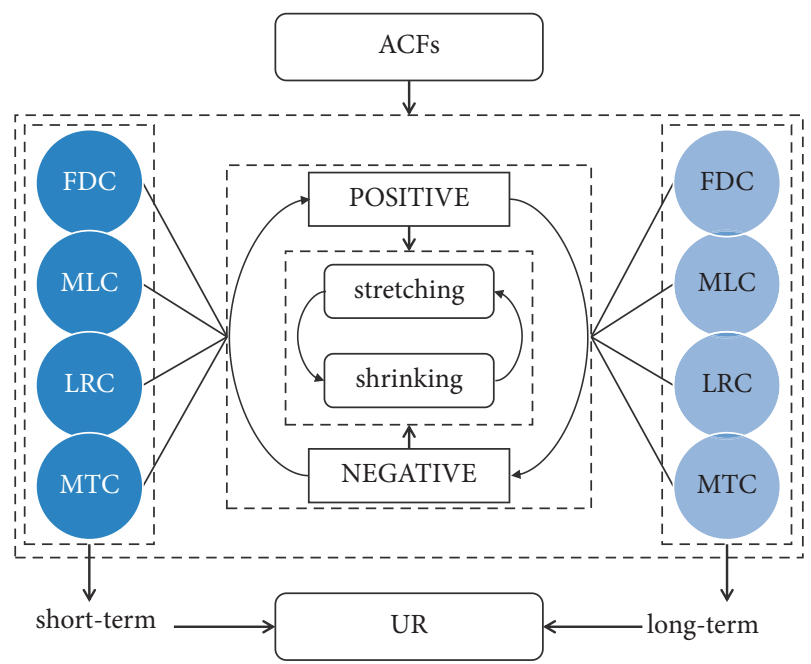

FIgURE 1: Analytical framework of relationships between ACFs and urbanization in Tibet.

urbanization. By contrast, if the food supply fails to meet the increased demand, food prices spike, which threatens industrial profits, investment, and economic growth [20]. Therefore, an insufficient food supply constrains urbanization.

Second, raw materials and labor are critical contributors to industrial development. Although not all industries require raw materials from the agricultural sector, for those that do (e.g., the textile, leather, shoe, food processing, and packaging industries), the cost of materials usually accounts for approximately one-third of the total cost of production [1]. The size of the occupational population in the agricultural sector is positively correlated with the level of productivity during a given period [1]. When technological changes occur in social productivity, occupational shifts occur among the population; such shifts are characterized by agricultural workers migrating away and switching to occupations in nonagricultural sectors [1].

Third, market contribution stimulates the expansion of industry, which promotes urbanization. The expansion of industry is stimulated by the exchange between industrial and agricultural sectors; this is because such an exchange increases not only the rural net cash income, but also the purchasing power of farmers [20]. Thus, agriculture provides the initial capital and market power for the expansion of industrial sectors.

On the basis of the preceding analysis, the following hypotheses were formulated.

Hypothesis 1: ACFs (i.e., FDC, MLC, LRC, and MTC) Granger-cause urbanization over the short and long term.

Hypothesis 2: FDC, MLC, LRC, and MTC strongly promote urbanization over the short and long term in Tibet, China.

Hypothesis 3: The effects of FDC, MLC, LRC, and MTC on urbanization are synchronous over the short and long term in Tibet, China. 
TABLe 1: Index systems of independent variables for the econometric model.

\begin{tabular}{|c|c|c|c|}
\hline ACFs & Descriptions & Unit & Direction \\
\hline \multirow{4}{*}{ FDC } & X11: Urban food consumption per year & $\mathrm{t}$ & + \\
\hline & X12: Quantity of surplus agricultural products per year & $\mathrm{t}$ & + \\
\hline & X13: Power of farm machinery & $\mathrm{kWh}$ & + \\
\hline & X14: Grain yield per hectare & $\mathrm{kg}$ & + \\
\hline \multirow{3}{*}{ MLC } & X21: Total value of agricultural-product-processing industry & $10,000 ¥$ & + \\
\hline & X22: Ratio of total value of agricultural-product-processing industry to total value of industry & $\%$ & + \\
\hline & X23: Ratio of agricultural commodities by value & $\%$ & + \\
\hline \multirow{3}{*}{ LRC } & X31: Agricultural labor input per unit of agricultural-product value & Person/100,000¥ & - \\
\hline & X32: Ratio of rural residents employed in agriculture & $\%$ & - \\
\hline & X33: Ratio of rural residents employed in nonagricultural sectors & $\%$ & + \\
\hline \multirow{3}{*}{ MTC } & X41: per capita savings deposit of urban and rural residents & $¥$ & + \\
\hline & X42: per capita rural expenditure & $¥$ & + \\
\hline & X43: Rural retail sales of consumer goods & $10,000 ¥$ & + \\
\hline
\end{tabular}

3.3. Dependent and Independent Variables. The dependent variable was the proportion of urban residents in Tibet (i.e., the population urbanization rate). The independent variables were selected based on a review of theoretical and empirical studies. All variables that were potentially suitable as parts of an econometric model are listed in Table 1. These independent variables are as follows.

(1) FDC: Ranis and Fei [6] defined the total agricultural surplus as the proportion of total agricultural output in excess of the consumption requirements of the agricultural labor force receiving an institutional wage. In other words, the relationships between food production, consumption, and surplus constitute a series of links, and these links are likely to affect urbanization. In this study, the variable "urban food consumption" (denoted X11) was used, which was a multiplier obtained by using the "food consumption of urban residents per year" and "total population of city" to represent the consumption link. Furthermore, this study used the difference that is "total yield of agricultural products" minus "total consumption of urban and rural residents" to explain the variable "quantity of surplus agricultural products," which was denoted as X12. Subsequently, "farm machinery" (denoted as X13 [37, 38]) and "grain yield" (denoted as X14 [38]) were chosen as independent variables; they have been widely used to explain levels of farming technology and food production to in turn represent the production link.

(2) MLC: the food processing industry is an important component of Tibet's industrial system [41] and has made considerable contributions to the local economy [50]. Therefore, this study identified 11 food processing industry sectors included in the Chinese government's statistical yearbook and calculated the total value (denoted as X21) and ratio (denoted as $\mathrm{X} 22$ ) of the agricultural-product-processing industry to total industry. Subsequently, the "ratio of agricultural commodities by value" (denoted as X23) was chosen as a measure of the raw materials provided by the agricultural sectors to the nonagricultural sectors through the commodification of agriculture [51]; data on this variable are commonly available.

(3) LRC: Johnston and Mellor [20] used the agricultural labor input per unit of agricultural-product value (denoted as X31) as a variable to explain the labor supply. Other alternative variables, such as the ratio of people employed in a primary industry and the number of rural laborers, were also employed $[18,38]$. This study used the "ratio of rural residents employed in agriculture" (denoted as X32) and "ratio of rural residents employed in sectors other than agriculture" (denoted as X33) to explain labor contribution.

(4) MTC: to explain the market contribution of agriculture, "savings deposit," "rural expenditure," and "retail sales of consumer goods" were used, which were denoted as X41, X42, and X43, respectively.

The data for 1990-2019 were obtained from the Tibetan Statistical Yearbook [52] and National Economic and Social Development of Tibet report. The data were log transformed to eliminate differences in scale between data types.

\subsection{Econometric Model}

3.4.1. Vector Error Correction Model. The model used in this study was a five-variable vector error correction (VEC) model. On the basis of agricultural contributions theory, this study employed FDC, MLC, LRC, and MTC as the endogenous variables. The VEC model was that of Zhang et al. [53], which is written as follows:

$$
\Delta y_{t}=\alpha E C M_{t-1}+\sum_{i=1}^{k} \alpha_{i} y_{t-i}+\sum_{i=1}^{k} \beta_{i} x_{t-i}+\varepsilon_{t}
$$

The various parts of equation (1) are described as follows. First, ECM is the error correction term calculated by the cointegration equation, which reflects the nonequilibrium error of the deviation from the long-term equilibrium relationships between variables. Second, $\alpha$ is the adjustment 
coefficient, which reflects the speed of change in the current period of the variable that returns to the long-term equilibrium relationship or eliminates the unbalanced error. If the adjustment coefficient is negative, the deviation from the unbalanced error is corrected. Otherwise, the error not only remains uncorrected, but also increases. Third, $y_{t}$ is the urbanization vector. Fourth, $x_{t}$ is the vector of FDC, MLC, LRC, and MTC. Fifth, $\varepsilon_{t}$ is the residual term. The lag length of the model, appropriate lag2, was determined using Akaike's criteria.

Prior to model analysis, a unit root test and cointegration test were used to verify that the model was accurate. These tests proceeded as follows.

(1) Unit root test: Standard estimation procedures cannot be applied to a model that contains a nonstationary variable [54], because it can result in a spurious regression. Therefore, this study employed the augmented Dickey-Fuller (ADF) unit root test to determine whether a series was stationary before the series was used in a model. The following regression model was analyzed $[55,56]$ :

$$
\Delta y_{t}=\rho y_{t-1}+\sum_{i=1}^{p-1} \beta_{i} y_{t-i}+\mu_{t}
$$

where $\rho=\sum_{i=1}^{p} \varphi_{i}-1 ; \beta_{i}=-\sum_{j=i+1}^{p} \varphi_{j} ; y_{t}$ is the vector of urbanization, FDC, MLC, LRC, and MTC; and $t=1,2, \ldots, T$. The null hypothesis in this ADF test was $\rho=0$ against the alternative hypothesis $\rho<0$. If the null hypothesis was accepted, $y_{t}$ was a nonstationary series. The series was then taken the unit root test in "first difference." This process was repeated until a stationary series was obtained.

(2) Cointegration test: Even if two time series are nonstationary, the linear combination of these series is stationary [57-59]. Thus, this study determined whether any combination of the series was cointegrated using the Johansen cointegration test [60], which is written as follows:

$$
\Delta y_{t}=\prod_{y_{t-1}}+\sum_{i=1}^{p-1} \Gamma_{i}+\Delta y_{t-i}+H x_{t}+\varepsilon_{t}
$$

where $\Pi=\sum_{i=1}^{p}\left(\varphi_{i}-I\right) ; \Gamma_{i}=-\sum_{j=i+1}^{p} \varphi_{j} ;$ and $y_{t}$ and $x_{t}$ are two series among the urbanization, FDC, MLC, LRC, and MTC variables. If $\prod y_{t-1}$ was stationary, the two series were cointegrated. If the variables were cointegrated, the VEC could be specified using the level data. Otherwise, the vector autoregression (VAR) model was employed using differenced data.

3.4.2. Granger Causality Test. The Granger causality test [61] was employed to evaluate the causal relationship between changes in agriculture and changes in urbanization in Tibet. An F-test was conducted to analyze the hypothesis that the FDC, MLC, LRC, and MTC of agriculture did not cause a change in urbanization.
3.4.3. Impulse Response Function and Variance Decomposition Analysis. The VEC has two main uses and has been widely used in empirical studies. The impulse response function (IRF) traces the effect of a one-time innovation shock to the explanatory variable on current and future values of the dependent variable. The variance decomposition (VD) is used to obtain information on the relative importance of explanatory variables [62].

IRF analysis was used to measure the effect of FDC, MLC, LRC, and MTC on current and future changes in urbanization. The vertical coordinate was the impulse power of urbanization (expressed as a percentage), and the horizontal coordinate was the time interval of the impulse (expressed in years). VD analysis was used to measure the relative importance of FDC, MLC, LRC, and MTC in explaining the variation in urbanization. The vertical coordinate was the percentage of variance in urbanization explained by a given independent variable, and the horizontal coordinate was the time interval of impulse (expressed in years).

\section{Results and Discussion}

\subsection{Growing Curves of Urbanization and ACFs in Tibet}

(1) Long-term urbanization in Tibet was characterized by a slowly increasing curve (Figure 2(a)). Tibet had an urbanization rate of $31.5 \%$ in 2019 , which was considerably lower than the national average in China of $60.6 \%$.

This urbanization curve for Tibet was divided into three periods: (1) 1990-2012, where the urbanization rate in Tibet increased steadily at $1.5 \%$ yearly to reach $22.7 \%$ in 2012; (2) 2012-2017, where the rate increased rapidly at $6.8 \%$ yearly to reach $30.9 \%$ in 2017 ; and (3) from 2018, where the rate slowed to $1.3 \%$ yearly. These results indicated that Tibet was still in an early stage of urbanization.

(2) The increasing curve of FDC indicated a decrease in surplus food in Tibet from 1990 to 2019; this decrease has accelerated since 2000 (Figure 2(b)).

The decrease in surplus food was closely related to food production and consumption. The food production output continued to increase from 1990 to 2019, and food consumption also increased due to the increase in the total population; moreover, the increase in food consumption has accelerated since 2000 , whereas the increase in food production has slowed. Thus, Tibet faces the challenge of producing sufficient food for its growing urban population.

(3) The increasing curve of MLC indicated that, from 1990 to 2019, the value of agricultural commodities in Tibet first increased to $60 \%$ in 2009 and then decreased to $51 \%$ in 2019 (Figure 2(c)).

In Tibet, the decline in the trade of agricultural products has meant that the need for raw materials by nonagricultural sectors has decreased since 2009 . The industrialization rate in Tibet was low and 


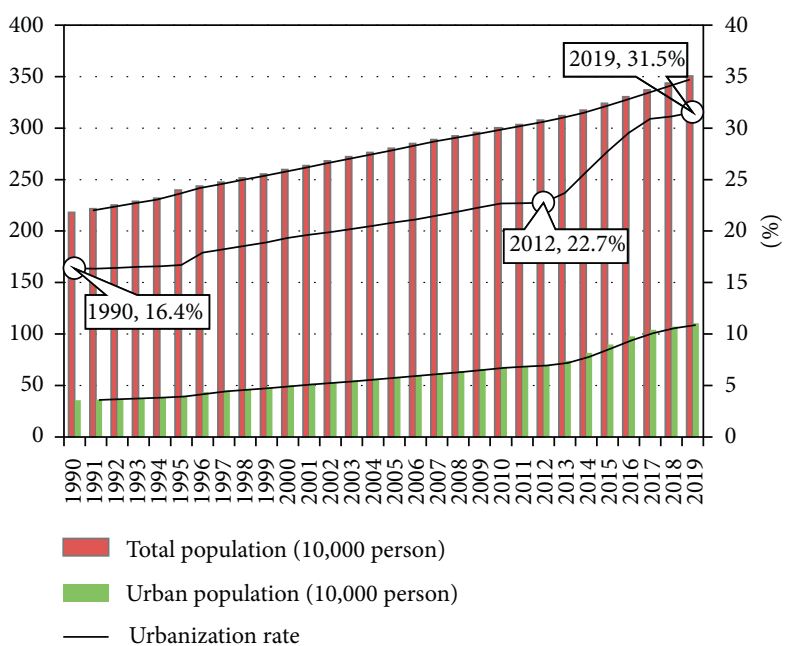

(a)

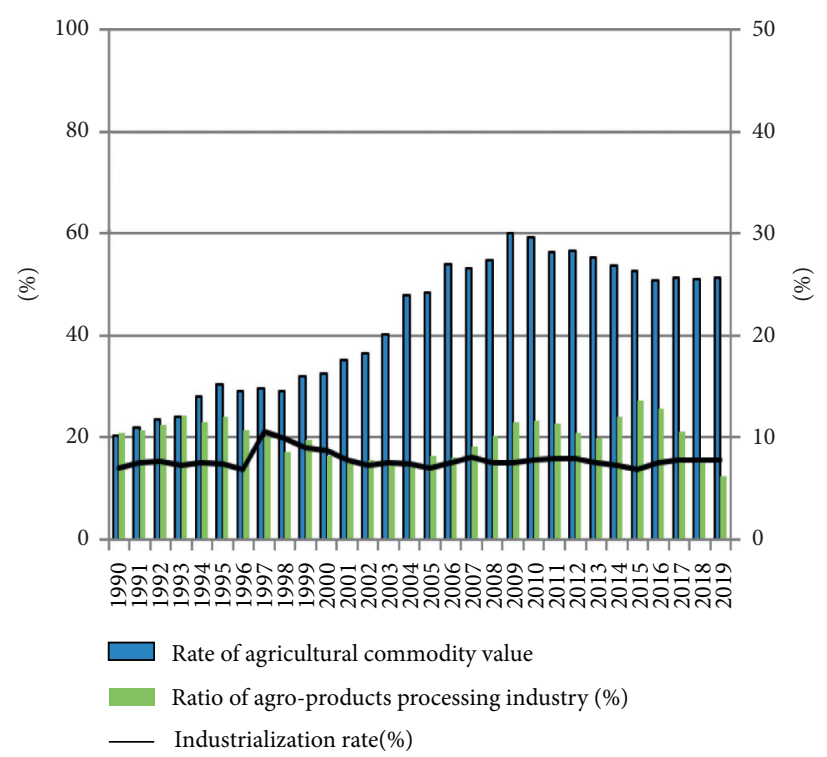

(c)

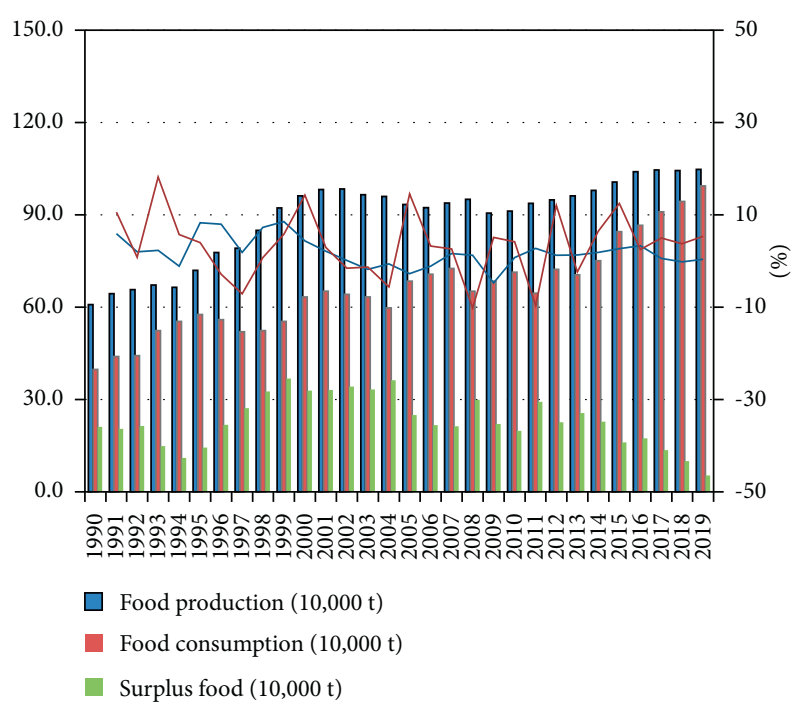

(b)

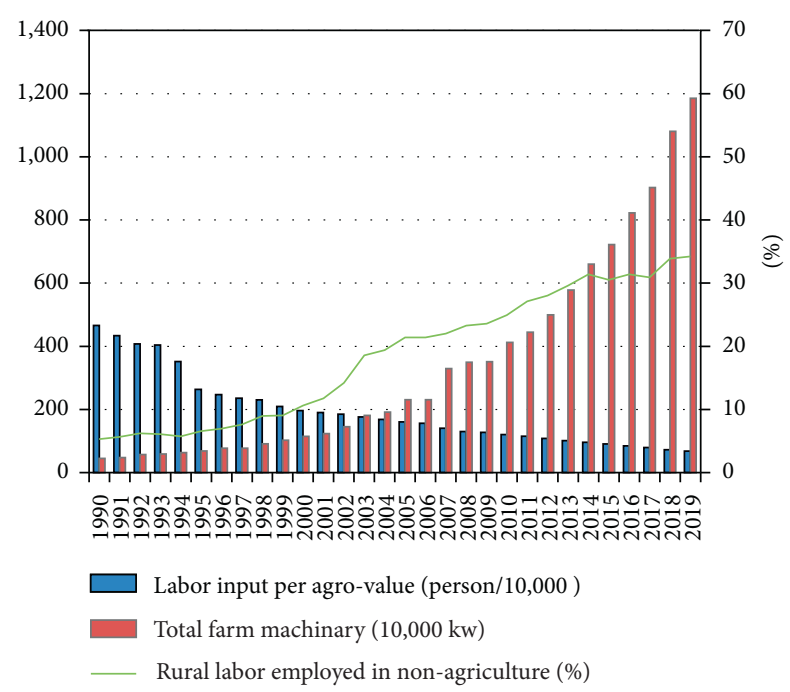

(d)

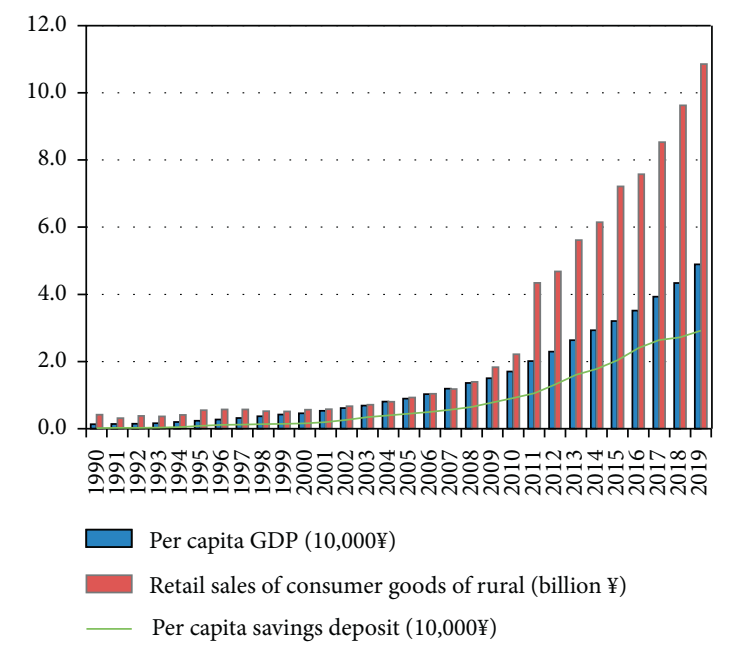

(e)

FIgUre 2: Curves of urbanization, FDC, MLC, LRC, and MTC in Tibet. (a) Urbanization. (b) FDC. (c) MLC. (d) LRC. (e) MTC. 
stagnant at $7.7 \%$ in most years between 1990 and 2019. The agricultural-product-processing industry constituted an important part of Tibet's industrial system, but the ratio of the total value of agriculturalproduct-processing industry to total industry output value exhibited a saddle-shaped growth curve, which fluctuated around $20 \%$. At present, Tibet's industrial structure is undergoing an adjustment away from light industry to heavy industry. The industrial output value of the agricultural-product-processing industry is likely to decrease in the future.

(4) The increasing curve of LRC indicated that agricultural labor efficiency in Tibet greatly improved from 1990 to 2019 (Figure 2(d)).

In 1990, 466 agricultural laborers produced every 100,000 RMB of agricultural output; this figure greatly decreased to 68 laborers in 2019, indicating that many laborers who were previously working in agriculture were released to other sectors. The rural employment structure in Tibet has also changed much. The proportion of agricultural laborers employed in nonagricultural work increased sharply from $5.3 \%$ in 1990 to $34 \%$ in 2019 . The construction $(10.7 \%)$ and transportation sectors (4.6\%) accounted for the largest share of the workforce in rural nonagricultural sectors in 2019; by contrast, manufacturing industry accounted for $2.6 \%$ of this workforce. In addition, the total power consumption of farm machinery increased from 4.5 million $\mathrm{kWh}$ in 1990 to 11.85 million $\mathrm{kWh}$ in 2019, which indicated a large increase in agricultural productivity in Tibet.

(5) The increasing curve of MTC indicated a continuous increase of per capita savings among both urban and rural residents in Tibet from 1990 to 2019 (Figure 2(e)).

In 2019, the per capita savings in Tibet reached 29,000 $\mathrm{RMB}$, much higher than the corresponding figure of 180 $\mathrm{RMB}$ in 1990 . This increase in per capita savings was closely related to improvements in the incomes and socioeconomic status of Tibet's residents. Among rural residents, higher incomes have not only increased savings, but also stimulated the consumption of products produced by secondary industries. These increasingly wealthy rural residents have formed a market that expanding urban industries have depended on.

4.2. The VEC Model. By employing the ADF unit root test (Table 2), the Johansen cointegration test (Table 3), and stability condition check (Figure 3), a VEC model was estimated (Table 4).

(1) For unit root test, $p$-value and Durbin-Watson statistic (DW-stat) were used to identify model specification and lag length at the level and at the first difference. For the identification of model specification, p-value of t-statistic of @TREND(“1990") and
C in variables less than 0.05 was used as standard to determine the correct type. Thus, types of intercept and trend, intercept, and none were separately estimated. For the identification of lag length, DW-stat approximately equal to 2 (the empirical value was between 1.8 and 2.1) was used as standard to determine the correct one. Thus, lags of 1,2, and 3 were separately estimated.

By doing this, we identified that LNy was a nonstationary series without trend and intercept and was stationary at the first difference, that is, I(1). At the same time, variables of LNx11, LNx13, LNx14, LNx23, LNx31, LNx41, and LNx42 were I(1) as well (Table 2). Then, it was possible to construct several vector autoregression (VAR) models. However, to further test the model VAR (2), we certified that $\mathrm{LNy}=f(\mathrm{LNx} 14, \quad \mathrm{LNx} 23, \quad \mathrm{LNx} 31, \quad \mathrm{LNx} 41)$, $\mathrm{LNy}=f(\mathrm{LNx} 11, \quad \mathrm{LNx} 23, \mathrm{LNx} 31, \mathrm{LNx} 42), \quad$ and $\mathrm{LNy}=f(\mathrm{LNx} 14, \mathrm{LNx} 23, \mathrm{LNx} 31, \mathrm{LNx} 42)$ had a stable VAR (2) (Figure 3). Ultimately, endogenous variables of X14, X23, X31, and X41 were used as indicators to interpret the FDC, MLC, LRC, and MTC of agriculture, respectively.

(2) Cointegration tests and VEC. As all variables were stationary at the first difference, we applied the Johansen cointegration test to examine whether a long-term relationship existed among the five variables. Trace statistics were significant for rejecting the null hypothesis of no cointegration ranging from 0 to 2 at most (Table 3). The adjustment coefficient $\alpha$ of the CointEq1 had two negative values (Table 4), indicating that the deviation from the unbalanced error would be corrected; i.e., the cointegration relationship was valid. At the same time, the cointEq1 showed that the change in UR in the short term was constrained by the long-term equilibrium relationship of five variables, namely, UR, FDC, MLC, LRC, and MTC. Then, a VEC was estimated (Table 4).

(3) For Granger causality tests, results of both the long and short term were estimated (Table 5). The results for the short-term Granger causality, which depends on data in the second column in Table 5, indicated that FDC, MLC, LRC, and MTC were Granger causes of urbanization; however, urbanization was not a Granger cause of FDC, MLC, LRC, or MTC. The results for the long-term Granger causality, which depends on the ECT(-1) term in the VEC model [63], indicated that urbanization itself, FDC, MLC, LRC, and MTC were long-term Granger causes of urbanization.

Thus, hypothesis 1 (that ACFs influence urbanization in Tibet over the short and long term) was verified.

4.3. Impulse Response Function Results. Figure 4 presents the results for the IRF for both the long (after 5 years) and short (within 5 years) term. 
TABLE 2: Results of the stationary process analysis for selected variables.

\begin{tabular}{|c|c|c|c|c|c|c|c|c|}
\hline ADF test & \multirow[b]{2}{*}{ LNy } & \multicolumn{3}{|c|}{ Level } & \multicolumn{3}{|c|}{$1^{\text {st }}$ difference } & \multirow{2}{*}{$\begin{array}{c}\text { Results } \\
\text { I (1) }\end{array}$} \\
\hline UR & & $\begin{array}{c}(\mathrm{C}, \mathrm{T}, \mathrm{K}) \\
(0,0,2)\end{array}$ & $\begin{array}{c}\text { DW-stat } \\
1.961\end{array}$ & $\begin{array}{c}\text { t-statistic } \\
2.409\end{array}$ & $\begin{array}{c}(\mathrm{C}, \mathrm{T}, \mathrm{K}) \\
(\mathrm{C}, 0,1)\end{array}$ & $\begin{array}{c}\text { DW-stat } \\
1.948\end{array}$ & $\begin{array}{l}\text { t-statistic } \\
-3.042^{\mathrm{b}}\end{array}$ & \\
\hline \multirow{4}{*}{ FDC } & LNx11 & $(\mathrm{C}, 0,2)$ & 2.065 & 3.288 & $(0,0,1)$ & 2.131 & $-2.016^{\mathrm{b}}$ & I (1) \\
\hline & LNx12 & $(0,0,1)$ & 1.826 & -0.876 & $(0,0,2)$ & 1.851 & -1.715 & I (2) \\
\hline & LNx13 & $(\mathrm{C}, \mathrm{T}, 1)$ & 2.030 & -2.261 & $(\mathrm{C}, 0,1)$ & 1.935 & $-4.728^{\mathrm{a}}$ & I (1) \\
\hline & LNx14 & $(\mathrm{C}, 0,1)$ & 1.902 & -2.522 & $(\mathrm{C}, \mathrm{T}, 1)$ & 1.927 & $-4.731^{\mathrm{a}}$ & I (1) \\
\hline \multirow{3}{*}{ MLC } & $\mathrm{LNx} 21$ & $(0,0,1)$ & 1.993 & 1.516 & $(0,0,1)$ & 1.976 & -1.643 & I (2) \\
\hline & $\mathrm{LNx} 22$ & $(\mathrm{C}, 0,2)$ & 1.958 & -2.351 & $(0,0,1)$ & 1.952 & -1.938 & I (2) \\
\hline & $\mathrm{LNx} 23$ & $(\mathrm{C}, 0,1)$ & 2.039 & -2.191 & $(0,0,1)$ & 2.161 & $-2.136^{\mathrm{b}}$ & I (1) \\
\hline \multirow{3}{*}{ LRC } & LNx31 & $(\mathrm{C}, \mathrm{T}, 1)$ & 1.922 & -2.679 & $(\mathrm{C}, 0,1)$ & 1.950 & $-4.252^{\mathrm{a}}$ & I (1) \\
\hline & LNx32 & $(\mathrm{C}, \mathrm{T}, 1)$ & 2.007 & -2.596 & $(\mathrm{C}, 0,1)$ & 1.945 & 22122.573 & I (2) \\
\hline & LNx33 & $(\mathrm{C}, 0,1)$ & 2.050 & -1.295 & $(0,0,2)$ & 1.938 & -1.068 & I (2) \\
\hline \multirow{3}{*}{ MTC } & LNx41 & $(\mathrm{C}, \mathrm{T}, 3)$ & 2.150 & -3.099 & $(\mathrm{C}, \mathrm{T}, 1)$ & 2.018 & $-4.784^{\mathrm{a}}$ & I (1) \\
\hline & $\mathrm{LNx} 42$ & $(\mathrm{C}, \mathrm{T}, 1)$ & 1.947 & -2.486 & $(\mathrm{C}, 0,1)$ & 2.054 & $-3.940^{\mathrm{a}}$ & I (1) \\
\hline & $\mathrm{LNx} 43$ & $(0,0,3)$ & 2.012 & 1.945 & $(0,0,1)$ & 2.095 & -1.398 & I (2) \\
\hline
\end{tabular}

Notes: $\mathrm{C}, \mathrm{T}$, and $\mathrm{K}$ are respectively the intercept, trend, and lag in the ADF test; ${ }^{\mathrm{a}}$ Indicates significance at the $1 \%$ level; ${ }^{\mathrm{b}}$ Indicates significance at the $5 \%$ level.

(1) As indicated in Figure 4(a), the response of urbanization to a positive shock in FDC pointed in the same and opposite direction as the FDC did before and after the seventh year, respectively. The reversed effect was long lasting and gradually increased in magnitude. The results indicated that, in Tibet, FDC stimulates urbanization in the short term but hinders urbanization in the long term.

This result is consistent with agricultural contributions theory on the mechanism linking FDC to urbanization. The aforementioned growth curve of FDC indicated increasing stresses on the food supply from the present rate of population growth under present levels of agricultural productivity.

The development of agriculture and urbanization in Tibet is inextricably linked to the continual assistance provided by the Chinese government for more than 60 years. Chinese government assistance to Tibet, primarily in farming machinery [64], farmland irrigation [65], agricultural technology, and agricultural expenditure $[64,66]$, has increased agricultural productivity and thus food production in Tibet.

The agriculture-related projects proposed in the third WFT (1994) by the Chinese government have completely transformed previously backward methods of agricultural production in Tibet. Grain output in Tibet increased rapidly throughout the 1990s, reaching 980,000t in 2002. The fourth WFT (2001) focused on urban development [67]. Thus, agricultural productivity changed little throughout the 2000s, and grain output increased slightly. The fifth WFT (2010) proposed a strategy for developing the countryside, and agricultural productivity increased again, with grain output reaching 1.05 million $t$ in 2019. At present, agricultural productivity in Tibet is relatively high, and grain output cannot be further improved through technological improvements [68]. Without food imports, urbanization in Tibet will be hindered by FDC in the long term.

(2) Figure 4(b) illustrates the reversed response of urbanization to a positive shock in MLC, which reached a maximum in the fifth year before weakening. The results indicated that MLC hindered urbanization in Tibet over the short and long term. These results elucidated the mechanism linking MLC to urbanization, as theorized in agricultural contributions theory. In Tibet, MLC hindered urbanization in small urban industrial sectors, especially in the agricultural-product-processing industry.

(v) The aforementioned growth curve of MLC indicated that the low industrialization rate could not stimulate urbanization, although the agricultural-productprocessing industries have been a critical component in Tibet's industrial system [69], contributing much to the local economy [50]. This result has two explanations. First, the high proportion and growth of the construction sector in the secondary industry displaced other secondary industrial sectors, hindering their growth. From 1990 to 2019, the proportion of the construction sector in the secondary industry increased from $46 \%$ to $82 \%$, whereas the proportion of manufacturing sector in the secondary industry decreased from $54 \%$ to $18 \%$. Second, the high growth of heavy industry in the secondary industry sector displaced light industry, hindering the growth of light industry. From 1990 to 2019, the proportion of heavy industry increased from $62 \%$ to $81 \%$, whereas the proportion of light industry decreased from $38 \%$ to $19 \%$.

The structure of national investment has resulted in the small scale and slow growth of the agriculturalproduct-processing industry in addition to the high 
TABLE 3: Results of Johansen cointegration tests.

\begin{tabular}{|c|c|c|c|c|}
\hline Hypothesized no. of cointegrating equation(s) & Eigenvalue & Trace statistic & 0.05 critical value & Probability \\
\hline None $^{*}$ & 0.869 & 136.839 & 69.819 & 0.000 \\
\hline At most $1^{*}$ & 0.792 & 81.983 & 47.856 & 0.000 \\
\hline At most $2^{*}$ & 0.613 & 39.640 & 29.797 & 0.003 \\
\hline At most 3 & 0.385 & 14.003 & 15.495 & 0.083 \\
\hline At most 4 & 0.032 & 0.877 & 3.841 & 0.349 \\
\hline
\end{tabular}

*denotes rejection of the null hypothesis at the $5 \%$ level.

cost of raw materials for this industry [1]; these have hindered the industry's growth. Thus, MLC hindered urbanization over the short and long term.

(3) Figure 4(c) indicates that the reversed response of urbanization to a positive shock in LRC reached a maximum in the third year. After the 15th year, however, the effect was in the same direction as LRC (LRC is a negative indicator). The results indicated that LRC promotes urbanization over the short term but hinders urbanization over the long term.

The results elucidated the mechanism linking LRC to urbanization, as theorized in agricultural contributions theory. For Tibet, when urban nonagricultural activities cannot absorb surplus rural labor, LRC stimulated urbanization over the short term but hindered urbanization over the long term.

The aforementioned growth curve of LRC indicated that, in Tibet, the agricultural labor required for a given unit of agricultural output decreased by $80 \%$ from 1990 to 2019. Furthermore, a large surplus of rural workforce meant that workers migrated to the cities for work. Among rural laborers in 2019, 34\% (approximately 494,000 people) worked in nonagricultural sectors, mostly in informal employment in the construction and transportation sectors [70].

The employment structure indicated that the surplus rural laborers in Tibet were passively absorbed into the urbanization process, and they had relatively few opportunities for formal employment-a situation made worse by the household registration system. Thus, flexible informal employment made it easy for rural laborers to switch between working in urban and rural areas, escaping from being marginalized in the urban labor market [71]. Therefore, LRC hinders urbanization over the long term.

(4) As illustrated in Figure 4(d), the response of urbanization to a positive shock in MTC was in the same direction as MTC; this response was long lasting and reached its maximum in the fifth year. The result indicated that MTC stimulates urbanization in both the short and long term.

This result is consistent with the mechanism linking MTC to urbanization, as theorized by agricultural contributions theory. The aforementioned growth curve of MTC indicated that the savings of rural residents in Tibet increased.

In rural areas, increased incomes and savings have stimulated consumption and production. Rural Tibet has thus provided a market for industry in urban Tibet. Rural residents now demand higher-quality industrial products, such as automobiles and home appliances, to improve their quality of life, thus increasing the total volume of consumer retail sales. From 1990 to 2019, this sales volume increased from 400 million RMB to 1.09 billion RMB. Furthermore, rural residents have increasingly purchased agricultural equipment (e.g., machinery, pesticides, and fertilizers) to save on human labor costs. The number of machinery units owned increased from 26,706 units in 1990 to 11.85 million units in 2019 (to almost five units of machinery owned per rural resident).

In summary, the growing consumption capacity of rural Tibet has stimulated urban industrial production, indicating that MTC simulated urbanization in the short and long term.

4.4. Variance Decomposition. The VD results are presented in Figure 5.

(1) The VD results indicated that the contribution rate of MTC to urbanization rapidly peaked at $23 \%$ in the fourth year before stabilizing (Figure 5). The results indicated that MTC responded quickly to changes in urbanization and acts as a key positive indicator of urbanization in Tibet at present and in the future. MTC was closely related to the growing demand for goods in rural Tibet to save human labor costs improve quality of life. This growing rural demand stimulated urban industry in particular and urbanization in general.

(2) The VD results indicated that the contribution rate of LRC to urbanization rapidly peaked at $39 \%$ in the second year before gradually decreasing to less than $10 \%$ in the 12 th year (Figure 5). The results indicated that LRC responded quickly to changes in urbanization and acts as a key positive indicator of urbanization in Tibet at present.

(3) The VD results indicated that the contribution rate of FDC to urbanization was small in the first 10 years before slowly peaking to $24 \%$ in the 13th year (Figure 5). The results indicated that FDC responded slowly to changes in urbanization and will act as a key negative indicator of urbanization in Tibet in the future.

(4) The VD results indicated that the contribution rate of MLC to urbanization peaked at $14 \%$ in the sixth year before gradually decreasing to less than $10 \%$ in the 


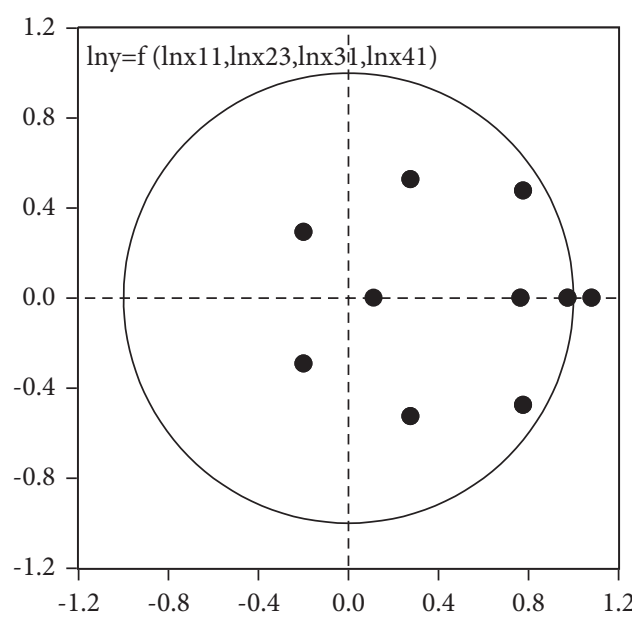

(a)

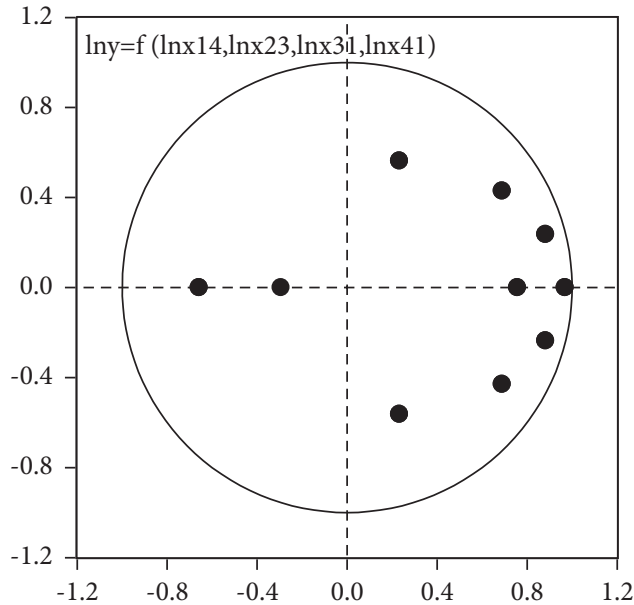

(c)

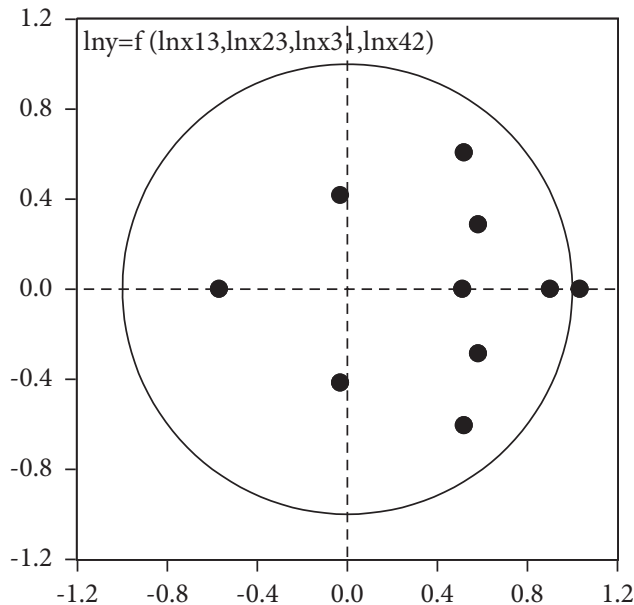

(e)

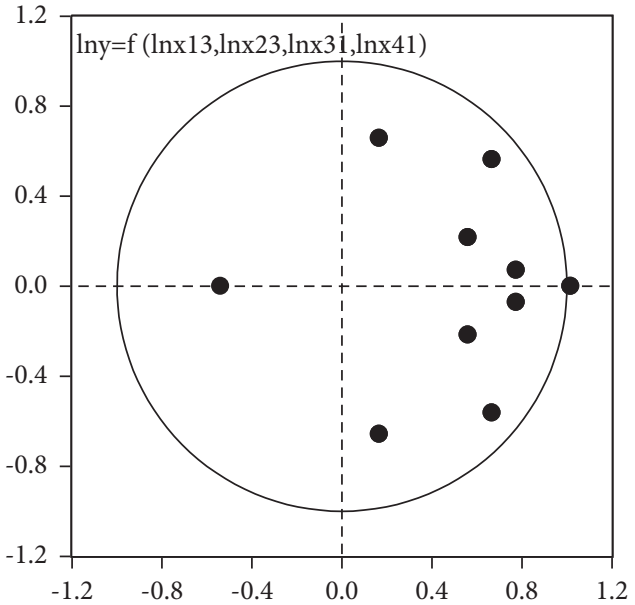

(b)

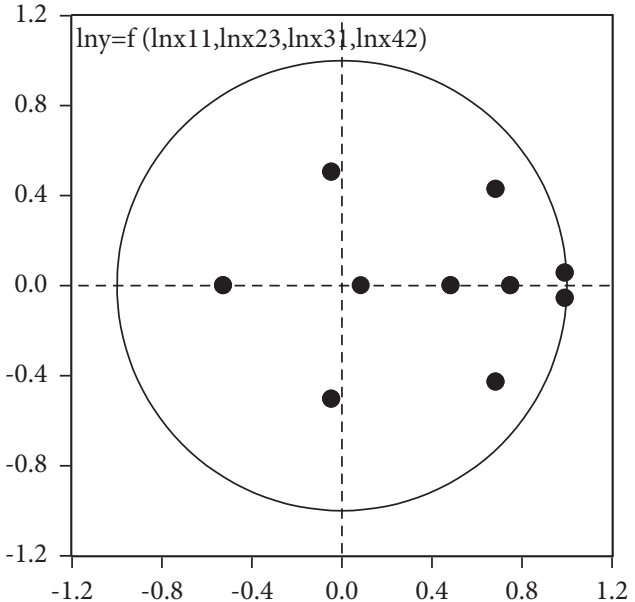

(d)

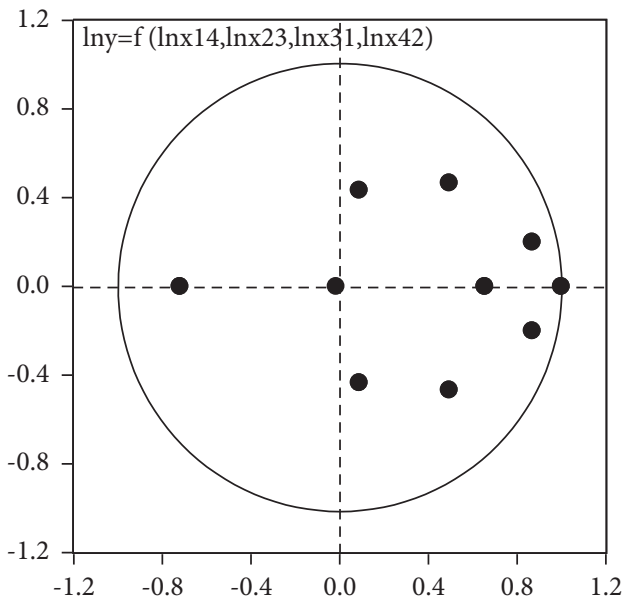

(f)

Figure 3: Stability condition check of VAR (2). 
TABLE 4: Results of VEC.

\begin{tabular}{|c|c|c|c|c|c|}
\hline $\begin{array}{l}\text { Cointegrating } \\
\text { Equation(s): }\end{array}$ & CointEq1 & CointEq2 & & & \\
\hline $\operatorname{LNUR}(-1)$ & 1.000 & 0.000 & & & \\
\hline $\operatorname{LNFDC}(-1)$ & 0.000 & 1.000 & & & \\
\hline $\operatorname{LNMLC}(-1)$ & $0.595(0.062)[9.625]$ & $\begin{array}{c}-0.296(0.131) \\
{[-2.265]}\end{array}$ & & & \\
\hline $\operatorname{LNLRC}(-1)$ & $\begin{array}{c}-0.791(0.187) \\
{[-4.240]}\end{array}$ & $\begin{array}{c}-1.686(0.394) \\
{[-4.277]}\end{array}$ & & & \\
\hline $\operatorname{LNMTC}(-1)$ & $\begin{array}{c}-0.539(0.073) \\
{[-7.347]}\end{array}$ & $\begin{array}{c}-0.737(0.155) \\
{[-4.754]}\end{array}$ & & & \\
\hline $\mathrm{C}$ & 1.388 & 3.154 & & & \\
\hline ErrorCorrection: & D(LNUR) & D(LNFDC) & D(LNMLC) & D(LNLRC) & D(LNMTC) \\
\hline CointEq1 & $\begin{array}{c}-0.263(0.055) \\
{[-4.751]}\end{array}$ & $\begin{array}{c}-0.309 \\
(0.130) \\
{[-2.373]}\end{array}$ & $\begin{array}{c}-0.210 \\
(0.403) \\
{[-0.521]}\end{array}$ & $\begin{array}{c}-0.061 \\
(0.400) \\
{[-0.153]}\end{array}$ & $\begin{array}{c}0.890 \\
(0.547) \\
{[1.628]}\end{array}$ \\
\hline CointEq2 & $0.030(0.024)[1.221]$ & $0.259(0.058)[4.496]$ & $0.157(0.178)[0.880]$ & $0.053(0.177)[0.302]$ & $0.001(0.242)[0.002]$ \\
\hline $\mathrm{D}(\operatorname{LNUR}(-1))$ & $0.794(0.121)[6.587]$ & $\begin{array}{c}-0.185(0.284) \\
{[-0.651]}\end{array}$ & $\begin{array}{c}-0.372(0.878) \\
{[-0.423]}\end{array}$ & $0.224(0.872)[0.257]$ & $0.581(1.192)[0.488]$ \\
\hline $\mathrm{D}(\operatorname{LNUR}(-2))$ & $\begin{array}{c}-0.421(0.107) \\
{[-3.931]}\end{array}$ & $0.148(0.252)[0.588]$ & $0.141(0.781)[0.180]$ & $\begin{array}{c}-0.212(0.775) \\
{[-0.274]}\end{array}$ & $\begin{array}{c}-1.116(1.060) \\
{[-1.053]}\end{array}$ \\
\hline $\mathrm{D}(\operatorname{LNFDC}(-1))$ & $\begin{array}{c}-0.362(0.116) \\
{[-3.128]}\end{array}$ & $\begin{array}{c}-0.691(0.273) \\
{[-2.536]}\end{array}$ & $0.082(0.844)[0.097]$ & $\begin{array}{c}-0.353(0.838) \\
{[-0.421]}\end{array}$ & $0.189(1.146)$ [0.165] \\
\hline $\mathrm{D}(\operatorname{LNFDC}(-2))$ & $0.004(0.107)$ [0.039] & $\begin{array}{c}-0.792(0.252) \\
{[-3.138]}\end{array}$ & $\begin{array}{c}-0.082(0.782) \\
{[-0.105]}\end{array}$ & $0.231(0.776)[0.297]$ & $0.778(1.061)[0.734]$ \\
\hline $\mathrm{D}(\operatorname{LNMLC}(-1))$ & $0.102(0.043)$ [2.385] & $0.004(0.101)[0.038]$ & $0.012(0.312)[0.040]$ & $\begin{array}{c}-0.154(0.310) \\
{[-0.497]}\end{array}$ & $\begin{array}{c}-0.292(0.424) \\
{[-0.689]}\end{array}$ \\
\hline $\mathrm{D}(\operatorname{LNMLC}(-2))$ & $\begin{array}{c}-0.063(0.037) \\
{[-1.728]}\end{array}$ & $0.038(0.086)[0.447]$ & $0.285(0.267)[1.068]$ & $0.156(0.265)[0.588]$ & $\begin{array}{c}-0.470(0.362) \\
{[-1.297]}\end{array}$ \\
\hline $\mathrm{D}(\operatorname{LNLRC}(-1))$ & $\begin{array}{c}-0.344(0.049) \\
{[-7.038]}\end{array}$ & $\begin{array}{c}-0.308(0.115) \\
{[-2.683]}\end{array}$ & $0.560(0.356)[1.574]$ & $0.006(0.353)[0.016]$ & $0.553(0.483)[1.146]$ \\
\hline $\mathrm{D}(\operatorname{LNLRC}(-2))$ & $\begin{array}{c}-0.060(0.069) \\
{[-0.880]}\end{array}$ & $0.109(0.161)[0.678]$ & $0.131(0.499)[0.263]$ & $\begin{array}{c}-0.227(0.496) \\
{[-0.458]}\end{array}$ & $1.008(0.678)$ [1.488] \\
\hline $\mathrm{D}(\operatorname{LNMTC}(-1))$ & $\begin{array}{c}-0.032(0.029) \\
{[-1.128]}\end{array}$ & $\begin{array}{c}-0.085(0.067) \\
{[-1.264]}\end{array}$ & $0.142(0.208)[0.685]$ & $\begin{array}{c}-0.206(0.206) \\
{[-0.997]}\end{array}$ & $1.108(0.282)$ [3.929] \\
\hline $\mathrm{D}(\operatorname{LNMTC}(-2))$ & $\begin{array}{c}-0.108(0.030) \\
{[-3.663]}\end{array}$ & $0.073(0.070)$ [1.047] & $\begin{array}{c}-0.066(0.215) \\
{[-0.307]}\end{array}$ & $0.012(0.214)[0.058]$ & $\begin{array}{c}-0.059(0.292) \\
{[-0.201]}\end{array}$ \\
\hline C & $0.009(0.002)[3.648]$ & $0.016(0.006)[2.880]$ & $0.025(0.017)$ [1.434] & $\begin{array}{c}-0.020(0.017) \\
{[-1.146]}\end{array}$ & $0.047(0.024)$ [2.009] \\
\hline $\mathrm{R}^{2}$ & 0.931 & 0.741 & 0.467 & 0.311 & 0.703 \\
\hline Adj. $\mathrm{R}^{2}$ & 0.871 & 0.519 & 0.010 & -0.279 & 0.448 \\
\hline F-statistic & 15.655 & 3.339 & 1.021 & 0.527 & 2.757 \\
\hline
\end{tabular}

Notes: Standard errors in round brackets; $t$-statistics in square brackets.

Table 5: Results of the Granger causality test.

\begin{tabular}{lcccccc}
\hline \multirow{2}{*}{ Dependent variable } & & \multicolumn{3}{c}{ Short-term causality } & \multicolumn{2}{c}{ Long-term causality } \\
& D(LNUR) & D(LNFDC) & D(LNMLC) & D(LNLRC) & D(LNMTC) & ECT(-1) \\
\hline D(LNUR) & & 0.485 & 0.187 & 0.089 & 1.140 & $6.587^{\mathrm{a}}$ \\
D(LNFDC) & $15.698^{\mathrm{a}}$ & & 0.052 & 0.660 & 0.662 & $-3.128^{\mathrm{a}}$ \\
D(LNMLC) & $10.687^{\mathrm{a}}$ & 0.202 & & 0.735 & 1.880 & $2.385^{\mathrm{a}}$ \\
D(LNLRC) & $52.364^{\mathrm{a}}$ & $10.168^{\mathrm{a}}$ & 2.572 & & 2.662 & $-7.038^{\mathrm{a}}$ \\
D(LNMTC) & $14.989^{\mathrm{a}}$ & 2.607 & 0.550 & 0.995 & & $-1.128^{\mathrm{a}}$ \\
\hline
\end{tabular}

${ }^{*}$ Null hypothesis: No causal relationship exists between the variables. ECT $(-1)$ was the error correction term that lagged by one period. ${ }^{\mathrm{a}}$ Indicates significance at the $1 \%$ level. ${ }^{b}$ Indicates significance at the $5 \%$ level. ${ }^{c}$ Indicates significance at the $10 \%$ level.

12th year (Figure 5). The results indicated that MLC responded slowly to changes in urbanization and acts as a relatively important negative indicator of urbanization in Tibet at present.
The results differed from theoretical expectations.

First, the impulse power of ACFs to changes in urbanization was less powerful than expected. For example, for a shock from FDC, MLC, LRC, and MTC, the maximum change in 


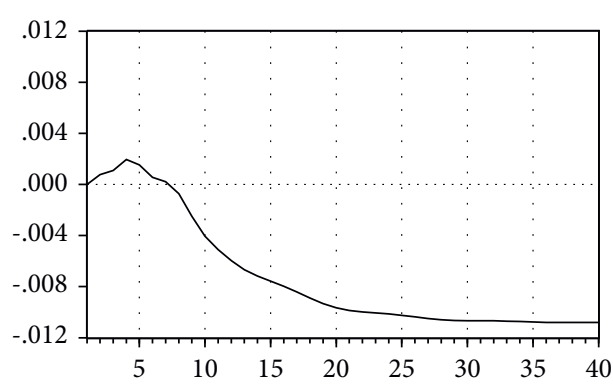

(a)

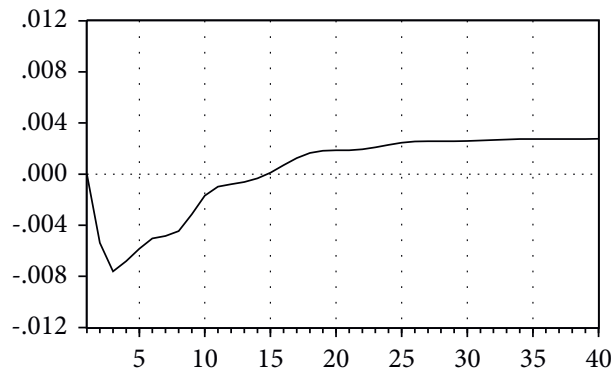

(c)

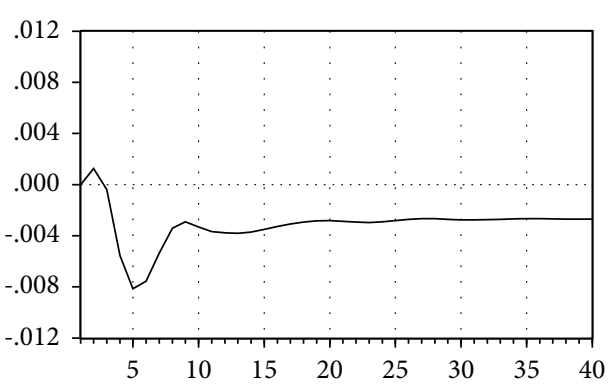

(b)

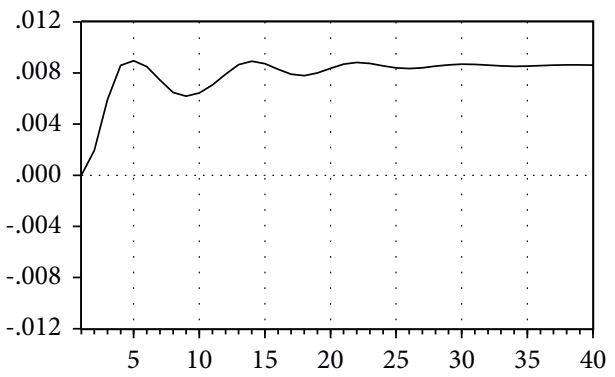

(d)

Figure 4: Response to a one standard-deviation Cholesky innovation of LNFDC, LNMLC, LNLRC, and LNMTC.

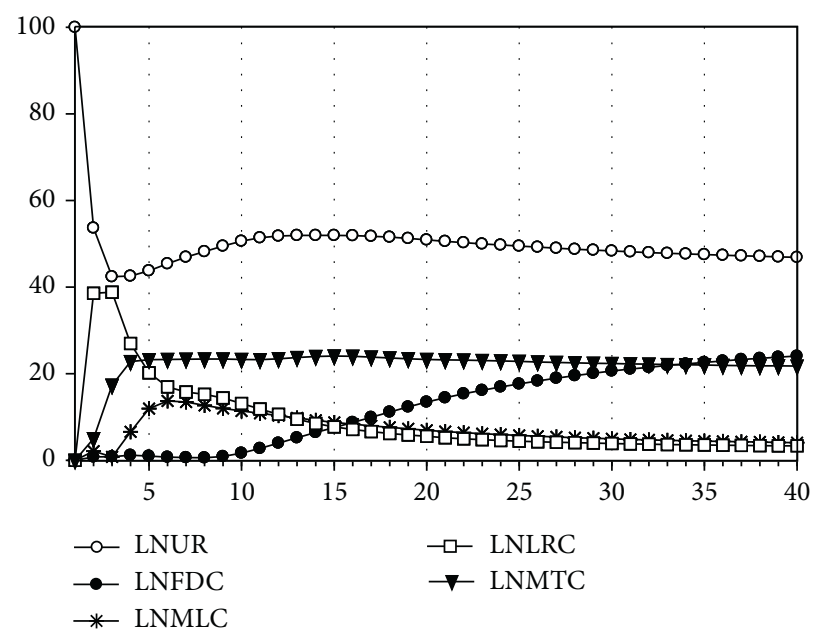

Figure 5: Variance decomposition of urbanization using Cholesky factors.

urbanization was small at $<0.012 \%$. According to development theory, agriculture greatly stimulates urbanization only if secondary industry greatly expands. Because Tibet's ecology is fragile, industrialization in Tibet was limited to a small scale [50]; this has greatly inhibited agriculture's ability to stimulate urbanization.

Second, LRC will hinder urbanization in the future. Studies have demonstrated that urbanization is stimulated by greater rural-to-urban migration $[72,73]$. In the dual social model, the surplus labor of the rural sector flows into secondary industry, leading to greater industrial production and urbanization. However, this process was likely to be distorted by the lack of rural push factors and urban pull factors. Johnston and Mellor [20] acknowledged that the transfer of workers from agricultural to nonagricultural sectors is stimulated by labor contribution but is hindered by rural population shortages and increases in agricultural output. However, in Tibet, rural push factors and urban pull factors will lead to LRC hindering urbanization in the future. First, religious beliefs and a lack of professional skills have made surplus rural laborers unwilling to migrate to the cities [70, 74]. Second, urban industry is too small to absorb the surplus of rural laborers [71], resulting in many rural migrants engaging in informal employment.

Third, policymakers in Tibet must coordinate agricultural modernization with urbanization. Agricultural modernization aids cities by providing food and raw materials but hurts cities by encouraging rural laborers to migrate to the cities, causing an oversupply of urban laborers. In Tibet, 
a tension is observed between such an oversupply and the excess demand from rural and urban areas. This structural tension between a high agricultural modernization level and a low urbanization level is becoming increasingly pronounced.

\section{Conclusions and Policy Implications}

This study (1) employed FDC, MLC, LRC, and MTC, as theorized in agricultural contributions theory, and (2) constructed a VEC model to analyze how and when ACFs influence urbanization in Tibet. Hypothesis 1 was verified, but hypotheses 2 and 3 were not. The results were as follows:

(1) ACFs Granger-cause urbanization over the short and long term; however, the dynamic is less powerful than expected.

(2) In Tibet, first, FDC and LRC stimulate urbanization at present but hinder urbanization in the future. This hindering effect increases over time, and FDC is more influential than LRC. Second, MLC hinders urbanization in Tibet over the short and long term. Third, MTC stimulates urbanization over the short and long term, and this stimulating effect peaks in the short term.

(3) First, FDC responds very slowly to changes in urbanization, and it will act as a key negative indicator of urbanization in Tibet in the future. Second, MLC responds slowly to changes in urbanization, and it acts as a relatively important negative indicator of urbanization in Tibet at present. Third, LRC responds quickly to changes in urbanization, and it acts as a key positive indicator of urbanization in Tibet at present. Fourth, MTC responds quickly to changes in urbanization, and it acts as a key positive indicator of urbanization in Tibet both at present and in the future.

This paper's findings have crucial policy implications. First, localized industries should be encouraged. This is because MTC consistently stimulates urbanization in Tibet both at present and in future, considering the current largescale consumption of consumer goods and agricultural equipment. Second, the government should train and educate rural residents and ensure the provision of more formal employment in cities. This is because LRC will hinder urbanization in Tibet in the future due to a dearth of skilled workers and formal employment. Third, and finally, the agricultural-product-processing industry should be expanded. This is because MLC hinders urbanization at present and will do so in the future, because the agriculturalproduct-processing industry is small and growing slowly.

This study has the two limitations. First, it was difficult to obtain the direct representative indicators that measure the ACFs; thus, the paper employed indirect variables to substitution. This potentially led to an overestimation or underestimation of agriculture's contribution to urbanization. Second, Tibet was not compared with another postindustrialized region, which limited the validity of this study's findings of agriculture's role in urbanization. Nonetheless, this study elucidated the influence of ACFs on urbanization; its findings are helpful to underdeveloped countries and regions other than Tibet in terms of policymaking. Furthermore, future studies could make consideration of openness in assessing impacts of agricultural contributions to urbanization.

\section{Data Availability}

The data used in this study are available from the first author upon request.

\section{Conflicts of Interest}

The authors declare that there are no conflicts of interest.

\section{Acknowledgments}

This work was supported by the National Social Science Foundation of China (Grant no. 17BRK010).

\section{References}

[1] P. Chang, Agriculture and Industrialization: the Adjustments that take Place as an Agricultural Country is industrialized, Harvard University Press, Cambridge, MA, USA, 1949.

[2] R. Antonietti and G. Cainelli, "Urban size and KIBS vertical disintegration: the case of Milan," European Planning Studies, vol. 24, no. 12, pp. 2241-2256, 2016.

[3] A. Scott, Metropolis: From the Division of Labor to Urban Form, University of California Press, Berkeley, 1988.

[4] M. Waiengnier, H. G. Van, R. Hendrikse, and D. Bassens, "Metropolitan geographies of advanced producer services: centrality and concentration in Brussels," Tijdschrift voor Economische en Sociale Geografie, vol. 111, no. 4, pp. 585-600, 2020.

[5] E. E. Lampard, "The history of cities in the economically advanced areas," Economic Development and Cultural Change, vol. 3, no. 2, pp. 81-136, 1955.

[6] G. Ranis and J. C. H. Fei, "A theory of economic development," The American Economic Review, vol. 51, no. 4, pp. 533-565, 1961

[7] E. S. Lee, "A theory of migration," Demography, vol. 3, no. 1, pp. 47-57, 1966.

[8] T. W. Schultz, "Reflections on investment in man," Journal of Political Economy, vol. 70, no. 5, pp. 1-8, 1962.

[9] M. P. Todaro, Economic Development in the Third World, Longman, New York, NY, USA, 3rd edition, 1985.

[10] D. Harvey, "The urban process under capitalism: a framework for analysis," International Journal of Urban and Regional Research, vol. 2, no. 1-3, pp. 101-131, 1978.

[11] H. Lefebvre, The Production of Space, Blackwell Publishing, Hoboken, NJ, USA, 1991.

[12] M. Castells, "The rise of network society," The Information Age: Economy, Society and Culture, Vol. 1, Blackwell Publisher, Cambridge, MA, USA, 2009.

[13] H. Chenery, S. Robinson, and M. Syrquin, Industrialization and Growth: A Comparative Study, Oxford University Press, New York, NY, USA, 1986.

[14] S. Kuznets, "Economic growth and the contribution of agriculture: notes on measurement," International Journal of Agrarian Affairs, vol. 3, no. 2, pp. 56-75, 1961. 
[15] W. W. Rostow, "The stages of economic growth," The Economic History Review, vol. 12, no. 1, pp. 1-16, 1959.

[16] H. Miranda, "The expansion of agriculture and its relationship with the urbanization process in the northeast region of Brazil (1990-2010)," Eure-Revista Latinoamericana De Estudios Urbano Regionales, vol. 38, no. 114, pp. 173-201, 2012.

[17] P. Richards, H. Pellegrina, L. VanWey, and S. Spera, "Soybean development: the impact of a decade of agricultural change on urban and economic growth in Mato Grosso, Brazil," PLoS One, vol. 10, no. 4, pp. 1-18, 2015.

[18] S. Tripathi and C. Rani, "The impact of agricultural activities on urbanization: evidence and implications for India," International Journal of Urban Sciences, vol. 22, no. 1, pp. 123-144, 2018.

[19] Z. Chen, R. Liu, B. Zheng, and Y. Zheng, "Study of internal mechanisms and relationships with simultaneous development about industrialization, urbanization and agricultural modernization," Research of Agricultural Modernization, vol. 33, no. 2, pp. 155-160, 2012.

[20] B. F. Johnston and J. W. Mellor, "The role of agriculture in economic development," The American Economic Review, vol. 51, no. 4, pp. 566-593, 1961.

[21] B. Christophers, "Revisiting the urbanization of capital," Annals of the Association of American Geographers, vol. 101, no. 6, pp. 1347-1364, 2011.

[22] D. Fields, "Urban struggles with financialization," Geography Compass, vol. 11, no. 11, pp. 1-13, 2017.

[23] D. Gollin, R. Jedwab, and D. Vollrath, "Urbanization with and without industrialization," Journal of Economic Growth, vol. 21, no. 1, pp. 35-70, 2016.

[24] D. Paul and T. James, "Agriculture and small towns in Africa," Agricultural Economics, vol. 44, pp. 449-459, 2013.

[25] G. F. Mulligan, "Revisiting the urbanization curve," Cities, vol. 32, pp. 113-122, 2013.

[26] C. Fang, X. Liu, and X. Lin, "Stages correction and regularity analysis of urbanization course of China," Arid Land Geography, vol. 31, no. 4, pp. 512-523, 2008.

[27] S. Ambinakudige and D. Parisi, "A spatiotemporal analysis of inter-county migration patterns in the United States," Applied Spatial Analysis and Policy, vol. 10, no. 1, pp. 121-137, 2017.

[28] T. O. Awokuse and R. Xie, "Does agriculture really matter for economic growth in developing countries?" Canadian Journal of Agricultural Economics/Revue canadienne d'agroeconomie, vol. 63, no. 1, pp. 77-99, 2015.

[29] I. Tsakok and B. Gardner, "Agriculture in economic development: primary engine of growth or chicken and egg?" American Journal of Agricultural Economics, vol. 89, no. 5, pp. 1145-1151, 2007.

[30] A. Tripathi, "Agriculture is still the engine of economic growth: empirical evidence from Uttar Pradesh, India," Asian Journal of Agriculture and Development, vol. 13, no. 1, pp. 1-20, 2016.

[31] R. Tiffin and X. Irz, "Is agriculture the engine of growth?" Agricultural Economics, vol. 35, no. 1, pp. 79-89, 2006.

[32] K. Matsuyama, "Agricultural productivity, comparative advantage, and economic growth," Journal of Economic Theory, vol. 58, no. 2, pp. 317-334, 1992.

[33] D. Guin, "Urban transition in West Bengal, India," Journal of Asian and African Studies, vol. 52, no. 8, pp. 1258-1276, 2016.

[34] R. Sarkar, "Urbanization in India before and after the economic reforms: what does the census data reveal?" Journal of Asian and African Studies, vol. 54, no. 8, pp. 1213-1226, 2019.
[35] M. Brückner, "Economic growth, size of the agricultural sector, and urbanization in Africa," Journal of Urban Economics, vol. 71, no. 1, pp. 26-36, 2012.

[36] X. Diao, P. Hazell, and J. Thurlow, "The role of agriculture in African development," World Development, vol. 38, no. 10, pp. 1375-1383, 2010.

[37] H. Jiang and Z. Wang, "Empirical analysis on the relationship among industrialization, urbanization and agricultural modernization in Jilin Province," Scientia Geographica Sinica, vol. 32, no. 5, pp. 591-595, 2012.

[38] C. Wang, F. Wang, and B. Wen, "Empirical analysis of the inner relationship and mechanism of urbanization, industrialization, and agricultural and husbandry modernization in Xinjiang, China," Research of Agricultural Modernization, vol. 36, no. 6, pp. 1007-1012, 2015.

[39] X. Fu, "An analysis of urbanization and its dynamical mechanism in Qinghai-Tibet Plateau," Journal of Natural Resources, vol. 15, no. 4, pp. 369-374, 2000.

[40] W. Tang, X. Zhong, and W. Zhou, "The evolvement and optimization of urbanization dynamics in "Three-River Area" on Tibetan Plateau," Journal of Mountain Science, vol. 29, no. 3, pp. 378-384, 2011.

[41] J. Fan and H. Wang, "Spatial analysis of population development and discussion of sustainable urbanization in Tibet," Scientia Geographica Sinica, vol. 25, no. 4, pp. 385-392, 2005.

[42] Z. Peng and Rongbazhaxi, "The empirical analysis of Tibet dual economy structure," Guizhou Ethnic Studies, vol. 28, no. 2, pp. 156-164, 2008.

[43] M. M. Xi, "Connotations and practical logics of Tibet's economic modernization: based on the spirit of the seventh symposium on work in Tibet," Tibetan Studies, no. S1, pp. 94-100, 2020.

[44] G. Cui and L. J. C. Ma, "Urbanization from below in China: its development and mechanisms," Acta Geographica Sinica, vol. 54, no. 2, pp. 106-115, 1999.

[45] Y. Ning, "New process of urbanization-dynamics and features of urbanization in China since 1990," Acta Geographica Sinica, vol. 53, no. 5, pp. 470-477, 1998.

[46] F. S. S. Victor and C. Yang, "Exo-urbanization: the case of the zhujiang river delta," Acta Geographica Sinica, vol. 52, no. 3, pp. 193-206, 1997.

[47] P. Chen, "The influence of the central supply model on the evolution of dual economic structure since the democratic reform in Tibet and its suggestions," Tibetan Studies, no. 2, pp. 86-93, 2019.

[48] B. Zikrya, S. Liu, B. Yu, and C. Zhou, "The influencing mechanism of Tibetan agricultural modernization on its urbanization," Researchof Agricultural Modernization, vol. 42, no. 5, pp. 1-10, 2021.

[49] J. Guo, "Coordination between urbanization and grain production security," Research of Agricultural Modernization, vol. 25, no. 4, pp. 279-282, 2004.

[50] G. Liu and L. Shen, "Characteristics and mechanism of Tibet's industrial structure evolution from 1951 to 2004," Acta Geographica Sinica, vol. 62, no. 4, pp. 364-376, 2007.

[51] M. Nassirou Ba, "Strategic agricultural commodity value chains in Africa for increased food: the regional approach for food security," Agricultural Sciences, vol. 07, no. 09, pp. 549-585, 2016.

[52] Duojizhandu, Tibet Statistical Yearbook 2016, China Statistics Press, Beijing, China, 2016.

[53] C. Zhang, K. Zhou, S. Yang, and Z. Shao, "Exploring the transformation and upgrading of China's economy using electricity consumption data: a VAR-VEC based model," 
Physica A: Statistical Mechanics and Its Applications, vol. 473, pp. 144-155, 2017.

[54] J. D. Hamilton, Time Series Analysis, Princeton University Press, New Jersey, USA, 1994.

[55] Y. Shih, H. Li, and B. Qin, "Housing price bubbles and interprovincial spillover: evidence from China," Habitat International, vol. 43, pp. 142-151, 2014.

[56] S. Wang, Q. Li, C. Fang, and C. Zhou, "The relationship between economic growth, energy consumption, and $\mathrm{CO}_{2}$ emissions: empirical evidence from China," The Science of the Total Environment, vol. 542, pp. 360-371, 2016.

[57] R. F. Engle and C. W. J. Granger, "Co-integration and error correction: representation, estimation, and testing," Econometrica, vol. 55, no. 2, pp. 251-276, 1987.

[58] S. Johansen, "Statistical analysis of cointegration vectors," Journal of Economic Dynamics and Control, vol. 12, no. 2-3, pp. 231-254, 1988.

[59] S. Johansen, "Time series: cointegration," in International Encyclopedia of the Social \& Behavioral Sciences, J. D. Wright, Ed., Elsevier, Oxford, UK, 2nd edition, 2015.

[60] M.-T. Lee, M.-L. Lee, and S.-H. Lin, "Trend properties, cointegration, and diffusion of presale house prices in Taiwan: can Taipei's house prices ripple out?" Habitat International, vol. 44, pp. 432-441, 2014.

[61] C. W. J. Granger, "Investigating causal relations by econometric models and cross-spectral methods," Econometrica, vol. 37, no. 3, pp. 424-438, 1969.

[62] C. Zhou, S. Wang, and K. Feng, "Examining the socioeconomic determinants of $\mathrm{CO}_{2}$ emissions in China: a historical and prospective analysis," Resources, Conservation and Recycling, vol. 130, pp. 1-11, 2018.

[63] G. Li, C. Fang, and S. Wang, "The effect of economic growth, urbanization, and industrialization on fine particulate matter (PM2.5) concentrations in China," Environmental Science \& Technology, vol. 50, no. 21, pp. 11452-11459, 2016.

[64] S. Hu, An Introduction to Agriculture of Tibet (In Chinese), Sichuan Publishing House of Science and Technology, Chengdu, China, 1995.

[65] J. Wang and C. Chen, Xizang Nong Mu Shi, Social Sciences Academic Press, Beijing, China, 2014.

[66] X. Fan, Xizang Nong Mu Ye Zeng Zhang Fang Shi Yan, China Agriculture Press, Beijing, China, 2007.

[67] X. Li, "The aid-for-Tibet drive and the changes in Tibetan economy and society over the past 50 years," Journal of Central University for Nationalities (Philosophy and Social Sciences), vol. 27, pp. 70-78, 2000.

[68] D. Long, T. Li, Y. Miao, and Z. Yu, “The spatial distribution and types of the development level of Chinese agricultural modernization," Acta Geographica Sinica, vol. 69, no. 2, pp. 213-226, 2014.

[69] J. Fan, "The formation of the locally-specialized system of the Qinghai-Tibet Region and its coordination with society, resources and environment," Resource Science, vol. 22, no. 4, pp. 12-21, 2000.

[70] Z. Zheng, "Research of the eastward floating of Tibetan population and the reconstruction of ethnic relations," Journal of Ethnology, no. 4, pp. 21-32, 2012.

[71] J. Li, "On surplus labor transfer and dual economic development in agricultural and pastoral areas in Tibet," Journal of Changzhou University, vol. 15, no. 1, pp. 45-47, 2014.

[72] N. Mohabir, Y. Jiang, and R. Ma, "Chinese floating migrants: rural-urban migrant labourers' intentions to stay or return," Habitat International, vol. 60, pp. 101-110, 2017.
[73] K. H. Zhang and S. F. Song, "Rural-urban migration and urbanization in China: evidence from time-series and crosssection analyses," China Economic Review, vol. 14, no. 4, pp. 386-400, 2003.

[74] J. Du, J. Sun, and W. Wang, "A survey on transfer of rural labor in Tibetan area of China," China Soft Science, vol. 31, no. 11, pp. 59-70, 2014. 